\title{
The use of carrageenan for limiting the mandibular movement in rats: A preliminary experimental study
}

\author{
Gabriela-Granja Porto ${ }^{2}$, Belmiro-Cavalcanti-do Egito Vasconcelos ${ }^{1}$, Valdemiro-Amaro Silva-Junior ${ }^{4}$, \\ Emanuel-Sávio-de Souza Andrade ${ }^{3}$
}

\begin{abstract}
${ }^{1}$ DDS PhD Postgraduate Student of the PhD program in Oral and Maxillofacial Surgery, University of Pernambuco, Recife, Brazil

${ }^{2}$ DDS MSc Senior Lecturer in Oral and Maxillofacial Surgery. Director of the Master and PhD programs in Oral and Maxillofacial Surgery, University of Pernambuco, Recife, Brazil

${ }^{3}$ DDS, MSc, PhD Senior Lecturer in Oral Pathology, University of Pernambuco, Recife, Brazil

${ }^{4}$ Senior Lecturer in Veterinary Histology, Federal Rural University of Pernambuco, Recife, Brazil
\end{abstract}

Correspondence:

Faculdade de Odontologia de Pernambuco

Departamento de Cirurgia e Traumatologia BMF

Av. General Newton Cavalcanti, 1650

Camaragibe - $P E$

54753-220 Brazil

belmiro@pesquisador.cnpq.br

Porto GG, Vasconcelos BC, Silva-Junior VA, Andrade ES. The use of carrageenan for limiting the mandibular movement in rats: A preliminary experimental study. Med Oral Patol Oral Cir Bucal. 2010 Jul 1;15 (4): $6553-7$.

http://www.medicinaoral.com/medoralfree01/v15i4/medoralv15i4p653.pdf

Received: 01/06/2009 Accepted: 23/12/2009

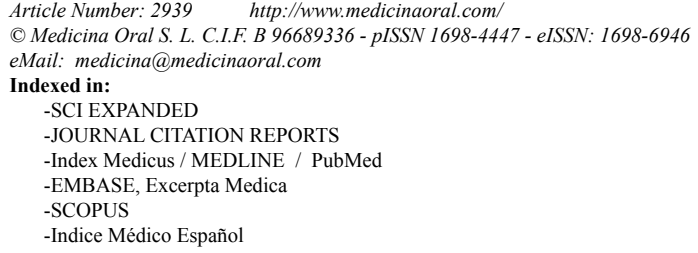

\begin{abstract}
Purpose: The objective of this study was to evaluate if the carrageenan may be used for limiting the mandibular movement.

Material and Methods: Eighteen adult male Wistar rats were used for the research, $20 \mu 1$ of carrageenan (4\%) was infiltrated in the extra articular region, in front of the condyle to induce fibrosis. The rats were divided into groups according to the time of euthanasia (7, 15 and 30 days). Maximal mouth opening (MMO), mandibular deviation, initial and final weights were recorded and evaluated. After the euthanasia, the specimens were submitted to histological study in order to classify the inflammatory process using scores.

Results: The mean differences between initial and final MMO were $1.50 \mathrm{~mm}$, being greatest at the 7 days evaluation and lowest at 30 days, and were not statistically significant at any time. No mandibular deviation was observed at any of the times of evaluation. The histological scores tended to increase with time of evaluation from 7 to 30 days, but without progression of the process.

Conclusion: The study model permitted the development of fibrosis in the extra-articular region in the majority of the animals.
\end{abstract}

Key words: Temporomandibular joint, temporomandibular joint disorders/surgery, Wistar rats/surgery. 


\section{Introduction}

Temporomandibular joint (TMJ) dislocation is defined as an excessive forward movement of the condyle beyond the articular eminence with complete separation of the articular surfaces and fixation in that position (1-3). It is commonly associated with poor development of the articular fossa, laxity of the temporomandibular ligament or joint capsule and excessive activity of the lateral pterygoid and infrahyoid muscles due to drug use or disease (1-4).

A variety of therapeutic approaches designed to limit the forward excursion of the condylar head have been applied, such as intra-capsular injection of sclerosing solutions (5), intra-muscle injection of botulinum toxin type A (6), lateral pterygoid myotomy (7), scarification of the temporalis tendon and bone grafting augmentation or application of a well-designed alloplastic impediment with vitallium mesh or titanium plates $(5,8)$. Another type of treatment is to reduce the eminence, thereby permitting free movement of the condyle (8). Each form of treatment described has its own advantages and disadvantages.

The placement of an obstacle in the articular eminence may result in limited mouth opening in some cases. Furthermore the removal of the eminence may lead to an articular degeneration. Adding to this, a surgical procedure always has a risk inherent to the procedure itself, such as intercurrences during the general anesthesia, facial nerve injuries and undesirable scaring; in addition to this the public health costs may be increased. Therefore the use of conservative methods is mandatory when it is indicated.

Carrageenan has been used as model of inflammatory hyperalgesia in joints in experimental studies using animal models (9-11). Thus the aim of this paper was to evaluate if the carrageenan may be used for limiting the mandibular movement in the quest for a conservative treatment for chronic mandibular dislocations using.

\section{Material and Methods}

The type of this study was an experimental animal model. The trial protocol was approved by the University's Ethics Committee. The research was made following the guidelines of the Brazilian School of Animal Research and the Universal Animal Rights of the United Nations Educational, Scientific and Cultural Organization. The sample size was estimated using the PCSIZE 1.1 program based on similar variables, this means based on the criteria described (12), and a correction factor of $20 \%$.

Eighteen male adult Wistar rats were used for the experiment. The rats were divided into groups of 6 animals each, according to the time of killing (7, 15 and 30 days).
Maximal mouth opening (MMO), weight and mandibular deviation were recorded and evaluated at the time of surgery and death, as well as the duration of surgery. MMO was measured from each incisal papilla because the teeth of this animal continue to grow throughout its lifetime.

Eighteen animals were subjected to surgery under general anesthesia, which was induced by muscular injection of ketamine and xylaxine diluted 1:1 in a dose of $0.1 \mathrm{ml}$ per $100 \mathrm{~g}$ of weight. For local anesthesia $0.2 \mathrm{ml}$ of lidocaine (1:200.000) was infiltrated. After that $20 \mu \mathrm{l}$ of carrageenan (4\%) was infiltrated extra articular, in front of the condyle.

After killing the rats, the joints were submitted to histological study in order to classify the inflammatory process using scores $(0=$ no fibrous tissue; $1=$ presence of fibrous tissue). The overall area of the extra articular infiltration was considered for this classification, using slides until the anterior area the joint was reached. The purpose was to detect the presence or absence of the tissues rather than quantify.

The specimens were fixed with Bouin solution for $24 \mathrm{~h}$ and were decalcified in a solution of formic acid $90 \%$ $(125 \mathrm{ml})$ and distillated water $(125 \mathrm{ml})$ and sodium citrate $(50 \mathrm{~g})$ and distillated water $(250 \mathrm{ml})$ for about 5 days. Semi-serial sections 5- $\mathrm{mm}$ thick were cut in the sagittal plane and stained with hematoxylin and eosin. For inferential evaluation the statistical study used the Wilcoxon Signed Posts and Student-t paired tests. The 0.05 level of significance was adopted for each test.

\section{Results}

During the experimental period, the animals lost weight in the first 7 days, after which they started to grow and gain weight until the end of the 30 days. Mean values of body weight of the animals were $392.66 \mathrm{~g}$ (day of surgery), $372.66 \mathrm{~g}$ (7 days of evaluation), $392.5 \mathrm{~g}$ (15 days) and $414.16 \mathrm{~g}$ (30 days). The mean differences between initial and final MMO were $1.50 \mathrm{~mm}$, being greatest at the 7 days evaluation and lowest at 30 days, and were not statistically significant at any time (Table 1). No mandibular deviation was observed. The histological scores tended to increase with time of evaluation from 7 to 30 days, but without progression of the process. The minimum scores were recorded at the 7 days evaluation and the maximum ones at 30 days (Table 2).

Histopathological findings

A histologically normal joint is shown in (Fig. 1A). At 7 days the presence of inflammation was observed in most of the animals in this group ( $\mathrm{n}=3$ ), with evidence of fibrosis in two animals (Fig. 1B). At 15 and 30 days there was fibrosis in all animals of these groups $(n=6)$ (Fig. 1C and D). 
Table 1. Maximal mouth opening according to time of evaluation and total group.

\begin{tabular}{|l|l|c|c|c|c|}
\hline & & \multicolumn{2}{|c|}{ Evaluation } & & \\
\hline Time of euthanasia & Statistics & Initial & Final & Difference & $\mathrm{p}$ Value \\
\hline 7 days & Mean $(\mathrm{mm})$ & 25.83 & 23.50 & 2.33 & $\mathrm{p}^{(1)}=0.068$ \\
\hline & Standard deviation $(\mathrm{mm})$ & 0.75 & 1.64 & 2.07 & \\
\hline 15 days & Variation coefficient $(\%)$ & 2.90 & 6.98 & $* *$ & \\
\hline & Mean $(\mathrm{mm})$ & 26.33 & 24.67 & 1.67 & $\mathrm{p}^{(1)}=0.102$ \\
\hline & Standard deviation $(\mathrm{mm})$ & 1.03 & 2.16 & 1.97 & \\
\hline 30 days & Variation coefficient $(\%)$ & 3.91 & & $* *$ & \\
\hline & Mean $(\mathrm{mm})$ & 24.83 & 24.33 & 0.50 & $\mathrm{p}^{(1)}=0.180$ \\
\hline & Standard deviation $(\mathrm{mm})$ & 1.17 & 0.82 & 0.84 & \\
\hline Total group & Variation coefficient $(\%)$ & 4.71 & 3.37 & $* *$ & \\
\hline & Mean $(\mathrm{mm})$ & 25.67 & 24.17 & 1.50 & $\mathrm{p}^{(2)}=0.002 *$ \\
\hline & Standard deviation $(\mathrm{mm})$ & 1.14 & 1.62 & 1.79 & \\
\hline & Variation coefficient $(\%)$ & 4.44 & 6.70 & $* *$ & \\
\hline
\end{tabular}

$(*)$ - Significant difference at $5.0 \%$.

$\left({ }^{*}\right)$ - Not determined because it tends in general to be a very high measurement in the variable difference.

(1) - Using the Wilcoxon Signed Posts Test. (2) - Using the Student 't' paired test.

Table 2. Histological scores according to time of evaluation and total group.

\begin{tabular}{|c|c|c|c|}
\hline Time of euthanasia & Scores & $\mathrm{N}$ & $\%$ \\
\hline \multirow[t]{2}{*}{7 days } & 0 & 3 & \\
\hline & 1 & 2 & \\
\hline 15 days & 1 & 6 & \\
\hline 30 days & 1 & 6 & \\
\hline \multirow[t]{2}{*}{ Total group ${ }^{\text {(A) }}$} & 0 & 3 & 17.65 \\
\hline & 1 & 14 & 82.35 \\
\hline
\end{tabular}

(A) - Loss of one result, due to the loss of histology material. 0 - Absence of fibrous tissue; 1 - Presence of fibrous tissue
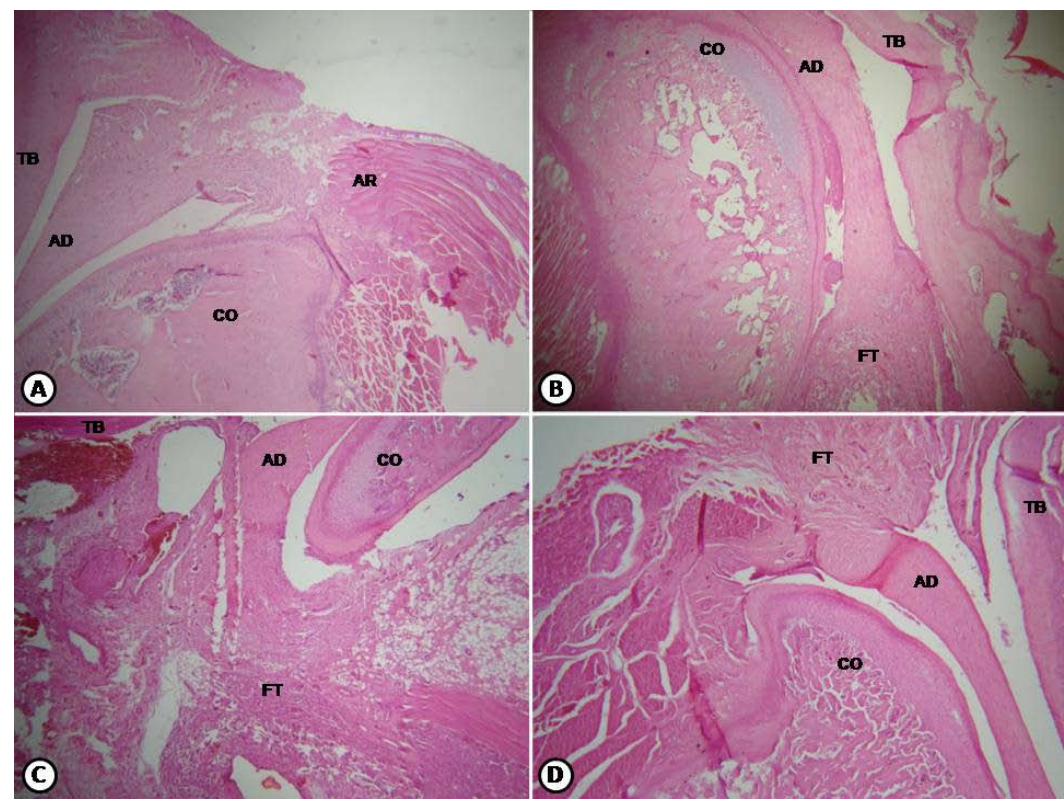

Fig. 1. $(A-D)$ : A - Anterior region of a normal temporo mandibular joint; B - Presence of fibrous tissue in the anterior area of the condyle at 7- dayevaluation; C - Presence of fibrous tissue in the anterior area of the condyle at 15 - day-evaluation; $\mathrm{D}$ - Presence of fibrous tissue in the anterior area of the condyle at 30- day-evaluation (40x H\&E) $(\mathrm{AR}=$ anterior region; $\mathrm{CO}=$ condyle; $\mathrm{TB}=$ temporal bone; $\mathrm{AD}=$ articular disk; $\mathrm{FT}=$ fibrous tissue). 


\section{Discussion}

Surgery is often appropriate when dislocation is prolonged or recurrent $(3,13)$, which requires a general anesthesia increasing public health expenses. On the other hand the surgical techniques may increase the patient's risk because these are invasive procedures. Thus the aim of this study is to turn the technique less invasive and onerous.

Numerous surgical procedures for habitual dislocation have been described in the literature based on creating a mechanical obstacle in the condylar path, such as positioning the disk anterior to the condyle, downfracturing of the zygomatic arch and fixation medial to the eminence or by the insertion of implants into the eminence $(3,14,15)$. In addition, there are other modes of treatment that aim to restrict movement of the condyle such as the injection of sclerosing substances or even the induction of fibrosis in the tissues adjacent to the joint $(14,16)$. Another type of treatment is to remove the mechanical obstacles in the condylar path; one such procedure is eminectomy, which was introduced by Myrhaug in 1951 $(1,15)$ and has been used with satisfactory results and efficacy according to the literature $(10,17,18)$.

No experimental studies have been published until now in the reviewed literature about this issue. Thus the comparative studies used in this investigation are most of experimental studies for ankylosis in sheep $(13,19,20)$ and rats (12) and condylar fractures in rats (21). Rats were the chosen animal because they are easy to handle and inexpensive to maintain in a bioterium, so it is convenient to use them in experimental studies.

It was observed that the mean difference between initial and final MMO decreased with time of evaluation up to 30 days until it was $0.5 \mathrm{~mm}$ in the 30 -day group. The differences were not statistically significant at any time of evaluation. These differences were expected to increase with time of evaluation $(12,20)$.

In relation to the histopathological findings, the presence of fibrosis in all animals was observed on 15 and 30 -day groups. It is possible to state that in $82.35 \%$ of the total group there was some kind of an obstacle in the periarticular region, since all the animals were classified as 1 (presence of fibrous tissue).

Bearing in mind that bone repair in rats takes around 21 days, it might be expected that the maximum evaluation time for detecting the degree of fibrosis after the induction process would be the first 30 postoperative days. This is in agreement with Luz et al. (21), since in their experiment with subcondylar fractures in rats the histopathological findings at 1 month revealed a normal joint, with no changes at the 90-day evaluation. According to these authors, in this study it was observed that the process did not evoluted until the 30 day of evaluation.

Considering both the histopathological and clinical fea- tures of this study, the tendency expected was that the greater the difference between initial and final MMO, more animals with extra- articular fibrosis would be found in each period of evaluation. This was not evidenced in the periods of evaluation or for each score, whether in isolation or when taking into account the difference between initial and final MMO. Also regarding the two forms of evaluation, it was not possible to state that there is a relationship between them. The explanation may be attributed to the high capacity for adaptation during the repair process of the studied animals. For this reason further studies with a larger sample need to be conducted.

Because the histopathological findings showed fibrosis in almost all animals, the extra articular use of carrageenan may be useful for treating temporomandibular joint chronic dislocation if used on clinical situations in humans. Despite the fact that the results cannot be extrapolated to humans because of the difference between the human species and that used in the study, the present paper contributes insights that will be value in major future studies on innovative treatments for this pathosis.

\section{References}

1. Cardoso AB, Vasconcelos BC, Oliveira DM. Comparative study of eminectomy and use of bone miniplate in the articular eminence for the treatment of recurrent temporomandibular joint dislocation. Braz J Otorhinolaryngol. 2005;71:32-7.

2. Hale RH. Treatment of recurrent dislocation of the mandible: review of literature and report of cases. J Oral Surg. 1972;30:527-30.

3. Vasconcelos BC, Porto GG, Lima FT. Treatment of chronic mandibular dislocations using miniplates: follow-up of 8 cases and literature review. Int J Oral Maxillofac Surg. 2009;38:933-6.

4. Poveda Roda R, Bagan JV, Díaz Fernández JM, Hernández Bazán $\mathrm{S}$, Jiménez Soriano Y. Review of temporomandibular joint pathology. Part I: classification, epidemiology and risk factors. Med Oral Patol Oral Cir Bucal. 2007;12:E292-8.

5. Bakardjiev A. Treatment of chronic mandibular dislocations by bone plates: two case reports. J Craniomaxillofac Surg. 2004;32:90-2.

6. Martínez-Pérez D, García Ruiz-Espiga P. Recurrent temporomandibular joint dislocation treated with botulinum toxin: report of 3 cases. J Oral Maxillofac Surg. 2004;62:244-6.

7. Laskin DM. Myotomy for the management of recurrent and protracted mandibular dislocations. Trans Int Conf Oral Surg. 1973;4:264-8.

8. Oztan HY, Ulusal BG, Turegun M, Deveci M. Titanium screw implantation to the articular eminence for the treatment of chronic recurrent dislocation of the temporomandibular joint. Int J Oral Maxillofac Surg. 2005;34:921-3.

9. Carmichael DJ, Gillard GC, Lowther DA, Handley CJ, Santer VB. Carrageenin-induced arthritis. IV. Rate changes in cartilage matrix proteoglycan synthesis. Arthritis Rheum. 1977;20:834-40.

10. Gardner DL. Production of arthritis in the rabbit by the local injection of the mucopolysaccharide caragheenin. Ann Rheum Dis. 1960;19:369-76.

11. Lundeberg T, Alstergren P, Appelgren A, Appelgren B, Carleson J, Kopp S, et al. A model for experimentally induced temperomandibular joint arthritis in rats: effects of carrageenan on neuropeptidelike immunoreactivity. Neuropeptides. 1996;30:37-41.

12. Porto G, Vasconcelos B, Silva V Jr. Development of temporomandibular joint ankylosis in rats: a preliminary experimental study. Int J Oral Maxillofac Surg. 2008;37:282-6. 
13. Miyamoto H, Kurita K, Ogi N, Ishimaru J, Goss AN. The effect of an intra-articular bone fragment in the genesis of temporomandibular joint ankylosis. Int J Oral Maxillofac Surg. 2000;29:290-5.

14. Kuttenberger JJ, Hardt N. Long-term results following miniplate eminoplasty for the treatment of recurrent dislocation and habitual luxation of the temporomandibular joint. Int J Oral Maxillofac Surg. 2003;32:474-9.

15. Sato J, Segami N, Nishimura M, Suzuki T, Kaneyama K, Fujimura K. Clinical evaluation of arthroscopic eminoplasty for habitual dislocation of the temporomandibular joint: comparative study with conventional open eminectomy. Oral Surg Oral Med Oral Pathol Oral Radiol Endod. 2003;95:390-5.

16. Puelacher WC, Waldhart E. Miniplate eminoplasty: a new surgical treatment for TMJ-dislocation. J Craniomaxillofac Surg. 1993;21:176-8.

17. Lovely FW, Copeland RA. Reduction eminoplasty for chronic recurrent luxation of the temporomandibular joint. J Can Dent Assoc. $1981 ; 47: 179-84$.

18. Oatis GW Jr, Baker DA. The bilateral eminectomy as definitive treatment. A review of 44 patients. Int J Oral Surg. 1984;13:294-8.

19. Matsuura H, Miyamoto H, Ogi N, Kurita K, Goss AN. The effect of gap arthroplasty on temporomandibular joint ankylosis: an experimental study. Int J Oral Maxillofac Surg. 2001;30:431-7.

20. Miyamoto H, Kurita K, Ishimaru J, Goss AN. A sheep model for temporomandibular joint ankylosis. J Oral Maxillofac Surg. 1999;57:812-7.

21. Luz JG, de Araújo VC. Rotated subcondylar process fracture in the growing animal: an experimental study in rats. Int J Oral Maxillofac Surg. 2001;30:545-9. 